\title{
La instauración del nacionalismo como política de Estado durante el gobierno del Cnel. Rafael Franco (1936 y 1937)*
}

\author{
Pedro Ramón Caballero Cáceres ${ }^{* *}$ \\ (caballero-pedro@hotmail.com)
}

Artículo de investigación recibido el 19/10/2014 y aprobado el 20/04/2015

\begin{abstract}
Cómo citar este artículo:
CABALLERO CÁCERES, Pedro Ramón (2015). "La instauración del nacionalismo como política de Estado durante el gobierno del Cnel. Rafael Franco (1936 y 1937)". En: Trans-pasando Fronteras, núm. 7, pp. 151-178. Cali, Colombia: Centro de Estudios Interdisciplinarios, Jurídicos, Sociales y Humanistas (CIES), Facultad de Derecho y Ciencias sociales, Universidad Icesi.
\end{abstract}

DOI: $10.18046 /$ retf.i7.1589

\section{Resumen}

El nuevo régimen surgido a partir de 1936 implantó un Nacionalismo que apuntó a despertar el orgullo nacional, un orgullo herido, engendrado en la derrota de la Guerra contra la Triple Alianza. Este despertar consistió en volver al pasado para proyectarse en el futuro. De esta forma la ideología nacionalista utilizó a la Nación como instrumento de concienciación histórica y política, configuran-

\footnotetext{
* La presente investigación forma parte de un trabajo más extenso que versa sobre la Instauración del Nacionalismo como Política de Estado durante el Gobierno del Cnel. Rafael Franco (1936-1937). El artículo pretende explicar las características que tomó el gobierno de Franco al adoptar el Nacionalismo como Política de Estado y qué repercusiones tuvo en la Nación paraguaya, entre ellas la re-escritura de la historia y las repercusiones en la memoria colectiva de los paraguayos.
}

** Profesor en la Facultad de filosofía de la Universidad Nacional de Asunción (UNA), Paraguay. 
do un nuevo panorama político que imprimió nuevos aires a la política paraguaya. El Nacionalismo implantado como Política de Estado tuvo hondas repercusiones en el país y afectó diversos ámbitos de la vida nacional. El nuevo régimen instaurado tras la Revolución de 1936 adoptó el Nacionalismo como Política de Estado, volviéndose a partir de allí un elemento gravitante en el sistema político. La adopción del Nacionalismo implicó una revisión del pasado nacional, con el objetivo de reivindicar figuras de la historia patria que habían sido vejadas y olvidadas por el modelo político implantado en el país tras la culminación de la Guerra contra la Triple Alianza, siendo considerados a partir de allí, los gobiernos de Francia y Carlos A. López, como modelos a seguir; al considerar, sus respectivos gobiernos, como paradigmas a imitar y posibilitar el triunfo del imaginario político militar nacionalista, que años más tarde, se trasformará en católico y colorado.

\section{Palabras clave}

Nación, Nacionalismo, Ideología Nacionalista, Patrian.

\section{Introducción}

La hecatombe del 70 significó el fin de una época y el comienzo de una nueva, y ello implicaba la adopción de un nuevo modelo de Estado y por ende, desechar todo lo relacionado con el pasado. La ideología liberal, implantada por los vencedores, repercutió en la percepción e interpretación del pasado nacional. Los seguidores del Liberalismo conceptualizaron de déspotas y autoritarios a los gobiernos del Dr. Francia y lo López, dejando a la Nación paraguaya huérfanas de héroes y autoestima.

El Nacionalismo que emergió con fuerza, caracterizando y dominando los aspectos político y cultural del siglo XX paraguayo, se mezcló con la figura del Mcal. Francisco Solano López, confundiéndose mutuamente, dando origen también al Lopizmo. La suma de un fuerte sentimiento antiliberal y el auge del Nacionalismo, sirvieron de campo fértil para el desarrollo de la campaña revisionista.

El nuevo régimen surgido a partir de 1936 implantó un Nacionalismo que apuntó a despertar el orgullo nacional, un orgullo herido, engendrado en la derrota de la Guerra Grande. Este despertar consistió en volver al pasado para proyectarse en el futuro. De esta forma la ideología nacionalista utilizó a la Nación como instrumento de concienciación histórica y política.

Todos estos acontecimientos, sumado al conflicto bélico con Bolivia, llevaron a la afirmación del Nacionalismo en el Paraguay y que la misma, a partir de 1936, ascienda a 
ser ideología de Estado, configurando un nuevo panorama político que imprimió nuevos aires a la política paraguaya.

Se busca con este tipo de interpretación histórica, mostrar la necesidad de una revisión de los acontecimientos históricos desarrollados en el siglo XX por que, según nos parece, son sumamente relevantes para comprender las características políticas y culturales de nuestro tiempo y porque el fenómeno nacionalista impactó, en gran medida, en los diversos aspectos de la sociedad paraguaya y latinoamericana.

En cuanto a la metodología, el trabajo, esencialmente histórico, se realizó dentro del marco de un enfoque cualitativo y estudio descriptivo - explicativo del tema tratado, aplicados para reconstruir el paisaje histórico paraguayo, correspondiente, en este caso, a la instauración del Nacionalismo como Política de Estado. Partimos de la Teoría de la causalidad histórica, ya que la misma apunta a explicar y comprender los acontecimientos históricos. Se procedió, asimismo, a un análisis teórico analítico del tema estudiado.

\section{EI Nacionalismo como Política de Estado}

El Nacionalismo en Latinoamérica fue consolidándose lentamente a partir de los procesos de emancipación; pero a finales del siglo XIX, y los primeros años del siglo XX comenzó a estructurarse de manera mucho más orgánica y formal. El Nacionalismo tuvo la virtud de lograr una gran aceptación en las distintas capas sociales y grupos políticos. Durante este período hubo una gran inmigración de europeos a América. La llegada de este contingente de personas provocó la eclosión de ideas y sentimientos racistas, xenófobas y nacionalistas, permitiendo la penetración de ideas nacionalistas en los sectores más necesitados de la sociedad.

La llegada de colonos europeos despertó a su vez ciertos temores a las clases pudientes. Los comerciantes e industriales temían la eclosión de una revolución socialista, razón por la cual apoyaban la idea de reforzar los valores y principios nacionalistas, buscando a su vez la instauración de un gobierno fuerte.

Pero el Nacionalismo no sólo era una respuesta a la penetración humana europea y el contagio de ideas revolucionarias, sino también buscaba ser un muro ideológico a la difusión del Liberalismo, del Capitalismo internacional y por consiguiente la penetración de capital foráneo en desmedro de las actividades económicas de la oligarquía local. 
En el caso paraguayo, el Nacionalismo se vinculó con el pensamiento antiliberal y autoritario, desarrollando las características de ser un movimiento socio-político, debido a que los artífices del movimiento nacionalista escarbaron en las raíces de la historia, buscando revitalizar la cultura de la nación por medio de diversas acciones, y una ideología política, con un discurso y lenguaje característico, en consonancia con su doctrina. En la década de 1920 se conformaron las fuerzas sociales que iniciaron las críticas contra el régimen liberal, destacándose el nacionalismo conservador. Estos movimientos tuvieron mucha influencia en los distintos estratos sociales, acelerando, en gran medida, la crisis del liberalismo en Paraguay.

La Guerra del Chaco vino a tapar, momentáneamente, la crisis del modelo liberal, pero una vez finalizada la contienda, su suerte estaba echada. La Revolución del 17 de febrero de 1936 derrumbó al anquilosado régimen liberal, sustituyéndolo por un nuevo gobierno y un nuevo modelo de Estado.

El gobierno del Coronel Rafael Franco inauguró un período caracterizado por la adopción del Nacionalismo como política de Estado y la emergencia de las Fuerzas Armadas como factor determinante en el quehacer político, siendo el actor preponderante del control estatal a partir de allí.

Las Fuerzas Armadas fueron el brazo armado de la revolución y asumieron el papel protagónico, significando un quiebre con las pautas de legitimidad. "El ejército irrumpe entonces en la escena y entra de lleno en el proceso de tomas de decisión" (Gatti, 1990: 44). La injerencia directa de la milicia en lo político se dio al crearse un espacio político provocado por una crisis hegemónica, la cual se vio acelerado por el conflicto chaqueño.

Partiendo de las ideas de Janowitz, la intromisión de los militares en política no se hubiera consumado en una sociedad tradicional donde están bien establecidas las instituciones, "cuando rige la sociedad tradicional, no se presenta el problema de la intervención militar, dada la legitimidad de las formas de gobierno y la coherencia de las pautas normativas" (Gatti, 1990: 45).

En este caso se aplica la teoría de Ernest Gellner, el cual sostiene que en una sociedad de transición de lo tradicional a lo moderno, siempre se genera un conflicto social e incoherencia en las normativas que rigen la vida de las instituciones. La agudización 
del conflicto favorece la injerencia de las Fuerzas Armadas, vistas por muchos como la única institución capaz de imponer el orden y devolver la estabilidad política.

El proceso de modernización en el Paraguay de inició a partir de 1910, con la instalación de las primeras fábricas. Este fenómeno se dio en un medio eminentemente rural y pre-industrial. La Guerra del Chaco aceleró este proceso y creó la concientización colectiva y el desarrollo de la autocrítica nacional, forjada en medio de la contienda chaqueña.

El gobierno revolucionario de febrero buscó la soberanía política y la independencia económica del Paraguay. Para ello era de suma importancia la revisión del pasado nacional, "la Revolución del 17 de febrero de 1936 buscaba la reivindicación de nuestra historia, como una parte, de la solemne, de la reivindicación nacional" (Rahi, 2001: 244-245).

El gobierno encabezado por Rafael Franco buscaba la "liberación integral del pueblo paraguayo" (Rahi, 1988: 19), con reformas en el campo político y económico, con una clara tendencia antiimperialista y de carácter revolucionario. Buscó ser una alternativa dentro del escenario político paraguayo, luego de una larga participación en el gobierno de los dos Partidos Políticos tradicionales.

A partir de 1936 se observa una ruptura con las líneas de pensamiento histórico de la clase dirigencial del país. Los hombres que llegaron al poder por medio de la gesta militar de febrero del 36' compararon dicho echo con otros acontecimientos históricos sumamente relevantes del pasado nacional.

Autores como Arturo Rahi y Anselmo Jover Peralta consideraron a la Revolución de 1936 como un nuevo intento del pueblo paraguayo de retomar las riendas de su destino. En ese sentido, ubican a la gesta de febrero al mismo nivel que la Revolución Comunera y la Revolución de Mayo. Los hombres de febrero tomaron como emblema de lucha la bandera caída en Cerro Corá, “la revolución aspira a reanudar la historia interrumpida en el 70' (...) aspirar a nacionalizar la economía desnacionalizada por la traición de los gobiernos anteriores” (Peralta, 1982: 13). De esta forma, el Nacionalismo apela a elementos ya existentes en el pasado nacional, pero al mismo tiempo la transforma y a su vez, crea otros nuevos elementos.

Con la ascensión del Coronel Rafael Franco a la primera magistratura, se coronó el largo proceso de reivindicación histórica iniciada por los Lopiztas y revisionistas del 
pasado nacional, que en sus comienzos mostró un carácter intransigente, girando en torno a la idea de mistificación de los gobiernos de Francia ${ }^{1}$ y los López. Pero como estuvimos analizando en los capítulos anteriores, el Lopizmo se asoció al Nacionalismo y en las primeras tres décadas del siglo XX se estructuró fuertemente, llegando incluso a formar parte de la ideología de la Asociación Nacional Republicana, conocido como Partido Colorado.

El gobierno de febrero con el Decreto $\mathrm{N}^{\circ} 66$, estipuló que el Mariscal Francisco Solano López sea considerado como "héroe nacional sin ejemplar" (Decreto $\mathrm{N}^{\circ} 66$ del Gobierno Provisorio). Para ello fueron derogados todos los decretos-líbelos emanados contra el Mariscal López desde 1869, "reputándoselos como no existentes” (Decreto $\mathrm{N}^{\circ} 66$ del Gobierno Provisorio). De un plumazo se eliminó para siempre los decretos antilopiztas de los Archivos Nacionales.

Toda la campaña reivindicativa iniciada por O’leary, a partir de este decreto, se hizo oficial y "su nacionalismo dogmático y estatista estaba en armonía con la dictadura de Franco" (Doratioto, 2002: 20). Disentimos en cuanto a la nominación de dictadura que Doratioto otorga al gobierno de Rafael Franco.

El culto a Solano López adquiere ribetes de reconstrucción nacional, de reparación de la nacionalidad que quedó huérfana y sometida a las fuerzas extranjeras. Juan Natalicio González, en su obra "El Paraguay Eterno” desarrolló la tesis de que el Liberalismo era una ideología exótica y foránea en el país, que se desarrollaba en contraposición a lo que el denominaba "esencia nacional", un concepto resultante de la tríada tierra, raza e historia, que él consideraba como esencia propia de la sociedad paraguaya, en un claro proyecto político que apuntaba con eliminar el orden liberal.

Siguiendo esa línea de pensamiento, Manuel Domínguez publicó en 1934 un extenso artículo en el que trataba de demostrar que el Paraguay de preguerra fue una Nación en

1 En esa búsqueda de los constructores de la nación paraguaya, vilmente destruida por las fuerzas de la Tríplice, los revisionistas del pasado nacional reivindicaron al Dr. José Gaspar Rodríguez de Francia, Carlos Antonio López y el Mariscal Francisco Solano López. Aún así, conviene señalar que la deificación del Dr. Francia está menos arraigada que la de los López. O’leary, en su libro sobre el Mariscal López, al expresarse sobre el gobierno del Dr. Francia hablaba de una "feroz tiranía", lo que llama poderosamente la atención. La reivindicación de la figura del Dr. Francia fue más bien obra de la izquierda paraguaya, en esa búsqueda constante de encontrar una figura nacional que se asocie a sus ideales. 
constante avance en contraposición a sus pares de la región. En el Paraguay antes del inicio de la guerra contra la Triple Alianza "no había una sola familia sin hogar (...).En instrucción primaria y con su escuela-taller, se adelantó a Europa y a América (...). Era el único país Sudamericano que no estaba en bancarrota, el único de moneda sana. (...). Ninguna nación americana le igualó en producción” (Domínguez, 1934: 65).

González, por su parte, consideró como factor clave del desarrollo del Paraguay la eliminación del liberalismo y para ello nuestro país "Necesita estrangular el Liberalismo sin piedad (...) Así tornará a ser la nación grande y fuerte que fundó la civilización en el Río de la Plata. La doctrina liberal es el veneno que emponzoña el alma de la patria" (González, 1986: 113).

Como vemos en las expresiones de J. N. González, existe una lucha entre lo autóctono, lo nacional, contra lo extranjero. En esa lucha contra el imperialismo, el Nacionalismo Lopizta fue visto como antiimperialista, como una corriente e instrumento que servía a los intelectuales nacionales para atacar al Liberalismo.

Es por ello que el Nacionalismo Lopizta fue adoptado por el gobierno de Rafael Franco, a pesar de que el Partido Liberal tenía sus propios héroes en la contienda chaqueña. Pero, el gobierno surgido en 1936 depuso a un régimen y buscó crear un nuevo modelo que se aleje del anterior. Ello implicaba la adopción de una ideología que concomitara con el nuevo régimen surgido tras la gesta armada, por ello la adopción del Nacionalismo Lopizta, representado por la figura del Mariscal López. " "El culto que se rendía a Solano López mostraba una concepción de estado favorable a un régimen de fuerza franquista, puesto que en el culto a Solano López el rol del ejército era trascendental" (Doratioto, 2002: 20).

El gobierno de Rafael Franco buscó darle al país su propia identidad, ya que la misma se encontraba en entredicho, de ahí las predicas de Natalicio González, ${ }^{3}$ Juan Emilia-

2 Al realizar los intelectuales la revisión del pasado nacional, centrado sobre todo en la figura del Mariscal Francisco Solano López, no sólo se procedió a la reescritura de la historia paraguaya, sino también originó la eclosión del nacionalismo indigenista. Precisamente, Natalicio González, perteneciente a este grupo, agregó, a su labor literaria, la utilización del Nacionalismo para fines de la praxis política. Ver: BAREIRO SAGUIER, Rubén. De Nuestras Lenguas y otros Discursos. La Generación Nacionalista - Indigenista del Paraguay y la cultura Guaraní. Volumen 34.Universidad Católica Nuestra Señora de la Asunción. Biblioteca de Estudios Paraguayos., Asunción, 1990.

3 Juan Natalicio González hacía la reivindicación del pasado nacional a través de la reivindicación de la 
no O’leary, ${ }^{4}$ Manuel Domínguez y Moisés Bertoni. ${ }^{6}$ El Nacionalismo hace hincapié en el redescubrimiento y la reconstrucción de la identidad nacional y para ello es de suma importancia redescubrir la cultura autóctona, de modo a fomentar los sentimientos de la comunidad nacional, por ello los fuertes componentes románticos y populistas que presenta dicha ideología. Si bien, ya desde la finalización de la Guerra de la Triple Alianza hasta el conflicto chaqueño, fue emergiendo una literatura historiográfica idílica e idealizante, que Francisco Pérez- Maricevich denominó "la ficcionalización de la historia o la historificación de la ficción" (Pérez-Maricevich, 1967: 57).

El Nacionalismo encontró un campo fértil en el período de postguerra, debido a la nueva realidad política, social y económica surgida tras la contienda bélica, caracterizada por un fuerte clima antiliberal, y encontró su brazo ejecutor en las Fuerzas Armadas. "El pujante nacionalismo de la postguerra chaqueña encontró, por tanto, que los militares eran el mejor símbolo de la soberanía nacional, triunfalmente ejercida contra un invasor extranjero" (Gatti, 1990: 41).

El auge del Nacionalismo a partir de 1936 fue debido a un proceso iniciado durante la década de 1920 y el cambio político operado por los militares, influenciados por las agitaciones populistas que enseñoreaban en América en esa época. El ejército se convirtió en el actor principal del cambio social que se observó en el país, principalmente en lo referente al sector campesino, grupo social que se vio aislado de los centros de poder al verse debilitado el caudillismo, tanto político como militar, y el sector obrero, organizado en sindicatos, pero que se desarrollaron fuera del gobierno de Rafael Franco.

El gobierno de febrero emitió diversos decretos de tinte nacionalista que significó la coronación de un largo proceso iniciado por los intelectuales nacionalistas. La revolución de 1936, además del auge del nacionalismo, significó la crisis hegemónica del Liberalismo por un lado, y la aceleración del proceso de modernización del país, por otro lado.

raíz indígena desde la perspectiva histórica y sociológica. Con respecto a su posición sobre la revolución de febrero, González, apoyó primeramente a dicho gobierno, inclusive en el exterior.

4 Juan Emiliano O’leary por su parte reivindicaba la figura del Mariscal López, Carlos Antonio López y el Dr. José Gaspar Rodríguez de Francia.

5 Manuel Domínguez teorizaba sobre el alma de la raza paraguaya, pero de forma lírica y con un exagerado optimismo nacionalista.

6 En cuanto a Moisés Bertoni, el mismo, teorizaba sobre la raíz indígena, pero desde un ángulo científico. 
Los decretos del gobierno de Franco de tinte nacionalista fueron:

1. Decreto $\mathrm{N}^{\circ} 23$. Asunción, febrero 26 de 1936, por la misma se constituye la comisión Pro-homenaje a la Memoria del Mcal. Presidente de la República, don Francisco Solano López,

2. Decreto $N^{\circ}$ 66. Asunción, Marzo $1^{\circ}$ de 1936, el cual declaraba Héroe de la Nación sin ejemplar al Mariscal Presidente de la República del Paraguay don Francisco Solano López y decretaba la erección de un monumento en su honor,

3. Decreto $N^{\circ}$ 514. Asunción, Marzo 31 de 1936, por el cual se confiere el ascenso póstumo a don Adolfo Rojas Silva y lo declara Héroe Nacional.

4. Decreto $\mathrm{N}^{\circ}$ 4834. Asunción, septiembre 14 de 1936, que declaraba beneméritos de la Patria al Dr. José Gaspar Rodríguez de Francia, a don Carlos A. López y al Mcal. Francisco Solano López, en calidad de Próceres de la Nación.

5. Decreto-Ley $\mathrm{N}^{\circ}$ 6227, del 2 de noviembre de 1936, por el cual se aumenta la pensión que el Estado acuerda a los veteranos de la Guerra contra la Triple Alianza.

6. Decreto $\mathrm{N}^{\circ} 4834$, del 14 de septiembre de 1936, que en su artículo $\mathrm{N}^{\circ} 1$ decretaba que el Oratorio de Nuestra Señora de la Asunción pasaba a designarse Panteón Nacional de los Héroes, destinándolo a conservar los restos de nuestros héroes.

7. Ley N 1070, mediante el cual se expropiaba la manzana donde está asentada el Panteón Nacional de los Héroes.

Todos estos decretos mencionados hacen alusión a figuras del pasado nacional. Como vemos, mediante estas leyes se reivindicaron las figuras político-militares del siglo XIX. El Dr. José Gaspar Rodríguez de Francia y los López, fueron elevados a la categoría de héroes nacionales. De un trazo, estas figuras pasaron de ser hombres cuestionados al rango de Próceres de la Nación. A ello se sumó la recordación de los excombatientes del 70' y la elevación a héroe del Tte. Adolfo Rojas Silva, primera víctima del conflicto chaqueño. No debemos olvidar que el Nacionalismo emerge ante una situación sociopolítica insatisfactoria, en el caso paraguayo, una derrota bélica. A partir de esto, se concibe un proyecto político que lleve a modificar la situación política reinante, y al mismo tiempo se vaya dotando, al proyecto, de una legitimidad y valor que lleve a su afirmación y valoración dentro de la comunidad que conforma una nación. 
En cuanto a los pueblos nativos, el decreto $\mathrm{N}^{\circ} 7389$ creó el Patronato Nacional de los Indígenas. La misma data del 10 de diciembre de 1936. El aspecto cultural no fue olvidado. El Decreto-Ley $N^{\circ} 10.680$ declaró Patrimonio Nacional las Ruinas y Obras de Arte Colonial, así como todo yacimiento u objeto arqueológico y paleontológico encontrado en nuestro país.

En cuanto al Decreto $N^{\circ} 511$, por esta Ley fue creada la Orquesta Folklórica Guaraní. La educación tampoco fue olvidada. El decreto $\mathrm{N}^{\circ} 2118$, del 18 de junio de 1936, estipuló las normas para la enseñanza nacionalista en las instituciones educativas.

Como vemos, el Nacionalismo fue adoptado como Política de Estado por el Gobierno del Coronel Rafael Franco y abarcó diversos aspectos de la vida nacional de dicho mandato, buscando frenar lo que Epifanio Méndez Fleitas denominaba "la técnica de desnacionalización del hombre paraguayo" (FLEITAS, 1971: 53). Es por ello que 1936 representa ya un intento de romper la tutela argentina sobre nuestro país.

En la suma de la reivindicación nacional, el punto central fue la reivindicación política, la legitimización de los gobiernos autoritarios, vistos por los revolucionarios como fundamentos y elementos claves de la nacionalidad. "Así como la república es el instrumento idóneo para conquistar la libertad enajenada por el pueblo a la monarquía, el despotismo es la práctica que permite que la nación recuperada se mantenga unida frente a eventuales conspiraciones extranjeras" (Delich, 2007: 160).

En este caso, el despotismo aparece como un elemento clave y extremo de alineación estatal y de la sociedad. El Nacionalismo emergente, apeló a la lengua nativa para acentuar las ideas de raza, unidad nacional, identidad nacional, ect., atrayendo a la masa popular, conformada en su mayoría por campesinos, sobre todo cuando estas ideas pasaron a conformar el corpus de las obras musicales, poéticas y literarias, dando origen, de esta forma a una especie de 'religión civil', como lo señala Giner.

\footnotetext{
(...) el declive de las religiones 'sobrenaturales' ha contribuido al surgimiento de una 'religión civil'; se refiere con esto a la sacralización de ciertos aspectos de la vida de la comunidad a través de rituales públicos, liturgias políticas o civiles y devociones populares, diseñadas para otorgar poder y reforzar la identidad y el orden dentro de sociedades heterogéneas. En ese contexto, la comunidad alcanza la trascendencia mediante sus símbolos y su historia épica (Guibernau, 2001: 57).
} 
A pesar del carácter secular del Nacionalismo, el mismo no dista mucho de ser una especie de religión política, debido a que ofrece una serie de prácticas, creencias y ritos que sirven de vínculo para los miembros de una determinada comunidad, de ahí la importancia de las fechas conmemorativas (fechas de batallas, recuerdo de la muerte de algún militar o líder político, etc.). Esta semejanza con la religión lo expuso magistralmente Durkheim.

Además, la concepción maniquea de la política, fue de suma utilidad para el poder autoritario-nacionalista que surgió como Política de Estado a partir de 1936 y que permanece hasta el presente.

\section{EI Discurso Nacionalista del Estado}

El gobierno de febrero se caracterizó por un claro discurso nacionalista, buscando de esa forma justificar sus acciones y, al mismo tiempo, acentuar la unidad del Estado, buscando ser, de alguna manera, la expresión de la voluntad del pueblo, con un vocabulario cotidiano que atraviesa las distinciones de clases. La evocación al Dr. Francia y los López fue con la finalidad de argumentar sus obras. Esto ya se observó en la proclama del Ejército Libertador, en el cual anunciaron:

\footnotetext{
(...) hombres y mujeres amantes de su tierra (habian luchado) contra un régimen de bandidos de levita sobornados por el extranjero y de asesinos empedernidos que, a través de varias décadas de violento predominio, ha terminado por constituir el foco infeccioso de los mayores males internos y externos que jamás hayan atacado, con mayor peligro de muerte, la salud moral y material de la República. (...) Vuestros soldados en armas juramos cumplir con nuestra misión: La Nación será restituida al nivel de su historia en el Río de la Plata, al libre dominio de su suelo y a la grandeza de su porvenir (Proclama del Ejército Libertador. Asunción, febrero 17 de 1936).
}

Ciertamente, la Revolución de 1936 siguió una política cuyo delineamientos, básicamente, fue la "convivencia con la oligarquía" (Campos, 1988: 456), debido a que en última instancia, la modernización del país, objetivo de la revolución, se lograría con la interacción con el capital extranjero, pero con una activa participación del Estado en la economía. 
El gobierno surgido tras la gesta armada del 17 de febrero de 1936 intentó desarrollar un proceso socio-político que buscaba formar un Partido Nacional Revolucionario, ${ }^{7}$ estructurado para responder a los intereses de los veteranos de la guerra, obreros, estudiantes y campesinos, buscando de esta forma tener consenso y legitimación.

Este gobierno que tuvo una duración de un año y seis meses fue el primer intento de revolución burgués impuesto desde abajo, pero el mismo fracasó debido a varios factores, entre ellos las desavenencias entre gremios de obreros y el gobierno. Pero el gobierno, básicamente, buscó establecer en el país una identidad nacional, de modo a lograr una unidad nacional y a partir de allí conseguir la autonomía nacional.

Tal como lo sostiene Eric Hobsbawm, el "nacionalismo (es) un modelo de ingeniería y control social en el que las élites canalizan y dan forma a las actividades y sentimientos de masas" (Smith, 2001: 102). La revolución de 1936 fue un movimiento ideológico que, por medio de la reivindicación de las figuras del pasado, buscó lograr y afianzar la unidad y autonomía nacional, objetivos de dicho gobierno. El discurso nacionalista, de esta forma, tuvo que generar un sujeto colectivo, que sirva de vínculo entre el pasado y las acciones del presente, y crear de esta forma un concepto de 'nosotros', unidos a través de símbolos y rituales, alrededor de los cuales una comunidad se siente identificada, y de esta forma conferir significado al Estado. El Nacionalismo, necesita hacer de su proyecto un plan que responda a la realidad nacional y sea el único que posea legitimidad. La oposición o la pertenencia a dicho proyecto político conllevan a la identificación o no de una comunidad determinada.

\begin{abstract}
La oposición y la adhesión al proyecto nacionalista hacen al sujeto merecedor de una calificación -o descalificación- mucho más radical y comprehensiva: "traidor" o "patriota", "vosotros" o "nosotros"... La valoración de estas posturas se lleva a cabo en términos de identificación o enajenación con la comunidad nacional, de fidelidad o infidelidad a ella (Cruz, s.a.: 123).
\end{abstract}

El Nacionalismo es una ideología que pone a la Nación en el centro de sus preocupaciones y por ende busca promover su bienestar en todos los ámbitos, es "básica-

$7 \quad$ Para conocer todo lo relacionado sobre la historia del Partido Revolucionario Febrerista ver el trabajo de CÉSPEDES, Roberto. El Febrerismo: Del Movimiento al Partido. 1936/1951. Asunción, Ed. Luxe, 1983, 168p. 
mente un principio que afirma la unidad política y nacional" (Hobsbawm, 1998: 17). El nuevo orden surgido a partir de 1936 configuró una nueva lectura y reescritura de la historia, llegando a consumarse el tercer estadio o fase del Nacionalismo según Eric Hobsbawm. ${ }^{8}$ De esta forma, la historia se convirtió en un elemento clave en este proceso de construcción de una Nación, "la historia es la materia prima más fácil de trabajar en el proceso de fabricar las naciones" (Hobsbawm, s.a.: 27). Al decir de Ernest Gellner, "el nacionalismo engendra naciones" (Gellner, 1997: 80). Son los intelectuales los autores principales de esta creación de "nueva nación" y en el caso paraguayo, esto es más palpable aún.

El gobierno revolucionario mostró su política nacionalista a través de varios decretos que fueron considerados "indispensables para proveer intereses vitales de la Nación" (Decreto $\mathrm{N}^{\circ} 2$ del Gobierno Provisional). En ese sentido, el gobierno de febrero buscó un cambio de estructura del régimen liberal. Esta nueva estructura debía conformarse de acuerdo a la "fisonomía y de la realidad orgánica natural de nuestra nación" (Declaraciones del Presidente de la República, Cnel. Don Rafael Franco).

En este sentido, las expresiones emitidas por el Cnel. Rafael Franco, se asocian a las ideas embanderadas por varios intelectuales paraguayos, sobre todo con J. Natalicio González, quien consideraba al Estado Liberal como fuerza exógeno, totalmente extraña a la idiosincrasia paraguaya.

La tarea de lograr la identidad y la unidad nacional giró en torno a la reconstrucción de la nacionalidad y para ello fue de suma importancia la utilización de todo tipo de símbolos y elementos que le confieren poder al nacionalismo, en ese trabajo constante de engendrar sentimientos que logren el sentido de pertenencia de los individuos a una comunidad específica.

Los símbolos utilizados en este caso fueron las figuras del Mcal. López, conceptuado a partir de allí como "Héroe Nacional sin ejemplar" (Decreto No 66. Artículo $2^{\circ}$. Asunción, Marzo $1^{\circ}$ de 1936), Carlos Antonio López y el Dr. José Gaspar Ro-

8 Según el historiador inglés Eric J. Hobsbawm, el Nacionalismo presenta tres fases. La primera es literaria y folklórica, en esta etapa no presenta influencias políticas. En la segunda fase, el Nacionalismo, encuentra apoyo en intelectuales que pregonan la idea de Nación, iniciándose por ende la campaña política que tiende a la expansión de las ideas; y en la tercera fase, el programa nacionalista comienza a adquirir importancia y sustento en las masas. 
dríguez de Francia, elevados a la categoría de "Próceres beneméritos de la Nación" (Decreto $\mathrm{N}^{\circ} 4834$. Artículo $2^{\circ}$. Asunción, septiembre 14 de 1936). Además de lugares de significación histórica, como el Oratorio de Nuestra Señora de la Asunción, transformado luego en Panteón Nacional de los Héroes, el Palacio de gobierno, el Teatro Nacional, la plaza Uruguaya, etc., lugares que recuerdan el pasado nacional evocado por el nuevo gobierno.

A ello sumamos la conmemoración de días festivos. El gobierno encabezado por el Cnel. Rafael Franco estipuló el $1^{\circ}$ de Marzo como Día de los Héroes, fecha que rememoraba la derrota del ejército paraguayo en la Guerra contra la Triple Alianza y la muerte del Mcal. Francisco Solano López. Todo esto apuntó a exhortar al individuo a ser partícipe de la ciudadanía y la comunidad nacional.

He aquí donde juega un rol importante el Estado. Como hemos mencionado anteriormente, el Estado tiene un discurso nacionalista y la misma es un mecanismo muy efectivo para tratar de lograr que los sujetos deseen lo que el Estado desea, es decir, que se identifiquen, pueblo y Estado, con los objetivos, fines y valores. De esta forma, los artífices de la revolución, diseñaron un proyecto político, que se caracterizó por la invocación del pasado para reforzar la unidad nacional y proyectarse al futuro. Así, pasado, presente y futuro se unen para darle forma y fundamento al carácter trascendente de la Nación.

En este punto se interrelacionan inevitablemente la memoria colectiva, la historia y la política. No existe grupo social que no tenga una memoria colectiva compartida, que constituya a su vez una identidad común que fortalezca los lazos de pertenencia, solidaridad y cohesión. De ahí la importancia de los símbolos, rituales, mitos, narraciones, etc., que son elementos compartidos por una comunidad y cuyas funciones son la de ser vínculos de unión y de conformación de voluntades comunes, base de la identidad nacional, de ahí la importancia de examinar los artefactos de la cultura política. Como sostiene Cohen, "(los símbolos) el medio ideal a través del cual la gente puede hablar un lenguaje 'común', comportarse de manera aparentemente similar, participar en los 'mismos' rituales" (Guibernau, s.a.: 95). El lenguaje, los símbolos, las palabras emitidas en un discurso, pueden crear realidades que no existen o existieron, y sostenerlas como existentes, creando héroes o villanos sociales, que se plasman en las mentalidades colectivas. 
Podemos afirmar que los hombres del gobierno de febrero se dotaron de una simbología que afirmó la continuidad de la tradición histórica por medio de los elementos citados con la finalidad de construir una identidad nacional y lograr, a partir de allí, la cohesión social y la legitimidad del régimen. La conciencia de pertenecer a una Nación deriva, necesariamente del hecho de compartir valores, tradiciones, recuerdos del pasado, y a eso apeló el gobierno. Meta que al final lograron, “(...) las dictaduras militares tramaron el tejido simbólico, organizaron el entorno de memoria, instalaron en la duración un metadiscurso sobre el pasado" (Capdevila, s.a.: 2).

Como vemos, el Nacionalismo es siempre un proyecto político y está direccionado ideológicamente a reglamentar y regular un estilo de vida de una determinada comunidad, caratulada como nacional, que no es sino la expresión de la misma. De esta forma, al utilizar un conjunto de símbolos, el Estado, por medio del discurso utilizado, encubre a su vez la diversidad interna que presenta y permite tapizar a la comunidad social de una cierta integridad ideológica.

En el discurso nacionalista de los hombres de febrero, dos son los elementos principales: la Nación y la Historia Patria. Los dos elementos son trabajados con el fin de producir estructuras sociales. No debemos olvidar que la identidad nacional es un producto cultural, por lo tanto artificial, debido a que se sostiene sobre símbolos inventados, con el objetivo claro de lograr y fomentar el sentido de pertenencia e identidad nacional.

De esta forma se logra que los individuos se sientan identificados con un "nosotros", como miembros de una comunidad, que lo diferencian de los "otros", y los símbolos, en este caso, funcionan como emblemas de distinción entre las dos categorías. Pero para que los símbolos no pierdan influencia ni continuidad en la memoria colectiva, los mismo necesitan ser reinterpretados y recreados constantemente, debido a que los símbolos están sujetos a una evolución, debido a que “(...) puede tener lugar no sólo de generación en generación, sino también dentro de una misma generación, puesto que el período de adquisición del simbolismo no se limita a una etapa cronológica particular" (Guibernau, s.a.: 96). Es una visión maniqueísta utilizada en la política para ser un elemento útil para el poder autoritario-nacionalista.

Como vemos, con el discurso nacionalista del Estado febrerista, se fue conformando las tres características básicas de la historiografía paraguaya: el Maniqueísmo, 
el Héroe Máximo y el Mito del eterno retorno. ${ }^{9}$ En cuanto a este último aspecto, los críticos al régimen liberal se centraron precisamente en que los mismos transformaron al país en un satélite de la Argentina. No debemos olvidar que para los nacionalistas la búsqueda de la soberanía económica es uno de los puntales de la campaña política, eso explica también la inclinación que tengan hacía la clase campesina, de modo a establecer un lazo emocional con el pueblo.

La lucha se centró entonces en lograr la autonomía nacional, soberanía que gozaba el país durante los gobiernos de Francia y los López. A partir de allí, dichos gobiernos, fueron considerados como una "Edad de Oro" de nuestra historia y todos los discursos nacionalistas se centraron en recrear esa época de "felicidad y prosperidad".

\begin{abstract}
Para los nacionalistas, el destino de la nación es siempre algo glorioso, como también lo es su lejano pasado; de hecho, las épocas doradas del pasado, ocultas tras el opresivo presente, volverán a brillar de nuevo en el futuro. (...) Así, el destino de cada nación no es retornar a un pasado glorioso, sino recrear su espíritu en los tiempos modernos y en nuevas condiciones (Smith, 2001: 47).
\end{abstract}

El Estado Nacional Revolucionario buscó establecer una autonomía nacional. Para ello buscaban la "dignificación y redención paraguaya (del Paraguay) y en tal sentido, nuestra redención es genuina y profundamente nacionalista". ${ }^{10}$

El intento de romper la dependencia económica hacía la Argentina se dio a través de varios proyectos de naturaleza intervencionista, natural en todo gobierno de naturaleza autoritaria. Esta política se vio favorecida también por la lucha hegemónica entre los EE.UU. de América y la Alemania Nazi, países que buscaban imponer sus ideas en Latinoamérica.

En cuanto a la Historia Patria, el Estado Revolucionario, hizo hincapié en una relectura de la historia nacional. El nuevo orden surgido tras la gesta armada del 17 de febrero de 1936 realizó una nueva ojeada de la "historia liberal". Como vemos, la clase dirigencial del nuevo Estado fijó su atención en el pasado, para, a partir de allí,

9 Ver el trabajo de Adriano Irala Burgos. La Epistemología de la Historia en el Paraguay.

10 Discurso del Presidente Provisional de la República, Coronel don Rafael Franco, pronunciado en la manifestación del $1^{\circ}$ de Mayo de 1936. 
reconstruir la historia nacional, imponiéndose, de esta forma, el pasado al presente, con una clara finalidad política.

Es interesante la construcción de la memoria colectiva que se fue conformando en nuestro país desde 1900 en adelante. Al respecto, Luc Capdevila escribió lo siguiente:

Desde luego, se podría observar aqui una construcción compleja de la memoria, donde el mantenimiento de una pregnancia inalterada del pasado/presente en el espacio social habría resultado de un doble movimiento. Primer movimiento, el del pasado que se impone al presente. O sea según una lectura psicoanalítica de la memoria, la existencia de un traumatismo enquistado en la conciencia colectiva cuya sociedad no puede superarse. Es la idea de un pasado que no pasa. El segundo movimiento está incluido en la Sociología de la memoria. Corresponde a la acción realizada por una sociedad en búsqueda de identidad, que al preguntarse sobre su porvenir busca respuestas en el pasado. Inventa así una tradición produciendo un relato y organizando un dispositivo conmemorativo para transmitir su representación del pasado a las generaciones siguientes (Capdevila, s.a.: 2-3).

Consideramos de suma importancia transcribir en extenso esta parte del trabajo de Luc Capdevila debido a que resume perfectamente el derrotero que tuvo la memoria histórica en nuestro país. Estos dos movimientos se observaron en nuestra sociedad en el período comprendido entre 1900 y 1930. En dicho período existía un grupo de excombatientes de la guerra grande que tenían una visión de la guerra, y por otra parte, el nuevo Estado surgido a partir de 1870 tenía su propia lectura.

Estas dos corrientes se oponían y esto originó que la nueva generación surgida tras la contienda bélica buscara sus propias respuestas a sus incógnitas. Esto ocasionó una nueva escritura de los relatos épicos de la guerra y una lucha con la "historia oficial" sostenida por el Estado Liberal.

La Revolución de 1936 vino a conformar el tercer movimiento, según el trabajo de Capdevila, al devenir el Nacionalismo en ideología de Estado creando una "simbiosis con el imaginario colectivo (haciendo) de la historia un instrumento fundamental de su dispositivo de encerramiento" (Capdevila, s.a.: 2-3) y con ello, lentamente, el revisionismo histórico adquirió el grado de "historia real". 


\section{El culto a la figura del Mcal. Francisco Solano López}

La figura del Mcal. Francisco Solano López fue la más atacada tras la finalización de la Guerra contra la Triple Alianza. Ya el decreto de 1869 lo vejaba al grado de declararlo "enemigo del género humano". Pero esta retórica era una política de los vencedores de relacionar al paraguayo pro-lopizta con la "barbarie", característica, según ellos, del Lopizmo.

Blas Garay fue el primer gran revisionista de la historia nacional. Sus ensayos sirvieron de base para estructurar el nacionalismo lopizta, que fue lentamente instituyéndose entre los intelectuales y militares. Luego, en la década de 1920, el movimiento historiográfico inició la campaña de la reivindicación del Mcal. López. En dicha década se recordaba dos grandes acontecimientos: el Centenario del natalicio del Mcal. Francisco Solano López y el cincuentenario de la finalización de la Guerra contra la Triple Alianza.

Además, en este período estaba latente el conflicto con Bolivia por la posesión del territorio chaqueño. Precisamente, en este punto dónde más reacias eran las críticas contra los gobiernos liberales, acusados de no tener una política de defensa de dicho territorio.

Las fuerzas sociales que aparecieron en dicha época relativizaron la importancia de los Partidos Políticos tradicionales y disminuyeron el rol ejercido por los caudillos políticos. Al mismo tiempo contribuyeron para reforzar, de alguna manera, el Nacionalismo conservador forjado por los intelectuales lopiztas. A partir de allí este nacionalismo comenzó a ganar espacio y respaldo en la sociedad paraguaya.

Juan Emiliano O’leary fue el gran propulsor de la reivindicación de la figura del Mcal. López. Ya en su polémica con Cecilio Báez en $1902^{11}$ sentó su postura sobre dicho tema. Inspirado en el pensamiento de Charles Maurras, O’leary desarrolló un nacionalismo integral en contraposición a la ideología liberal.

De la mano de este intelectual la figura del Mcal. López se fue transformando de asesino de su Patria a constituirse en constructor y forjador de su pueblo. Es decir, hay un cambio del rol histórico de Francisco Solano López en las páginas de la historia para-

11 Básicamente, la polémica entre ambos, iniciada el 18 de octubre de 1902 y culminada el 11 de febrero de 1903, giró en torno a la interpretación de la historia nacional, más que una lucha entre lopiztas y antilopiztas. Más bien, parece un quiebre generacional entre los jóvenes novecentistas y el maestro Cecilio Báez. No debemos olvidar que el Dr. Cecilio Báez reivindicó la figura del Dr. José Gaspar Rodríguez de Francia en 1888 y la misma se encuadra también dentro de los lineamientos del revisionismo histórico. Ver, Polémica sobre la Historia del Paraguay. 
guaya. Pero ya antes del inicio de la Guerra del Chaco, y a pesar de la importante labor desplegada por O’leary, el concepto que tenían sobre el Mariscal López, fue cambiando lentamente en el pueblo paraguayo.

Durante las primeras tres décadas del siglo XX el lopizmo se fue estructurando fuertemente y ocupó espacios en la vida nacional. El conflicto chaqueño fue el combustible necesario para la consolidación de la ideología nacionalista y la Revolución del 17 de febrero de 1936 lo catapultó como política de Estado.

El gobierno de Rafael Franco se abocó a la tarea de la revisión del pasado nacional. Ya en la Proclama del ejército hacedor de la revolución de febrero proclamaron que " $\mathrm{La}$ Nación será restituida al nivel de su historia en el Río de la Plata (...) y a la grandeza de su porvenir" (Proclama del Ejército Libertador. Asunción, febrero 17 de 1936).

$\mathrm{La}$ apoteosis del Mcal. Francisco Solano López se consumó con el decreto del $1^{\circ}$ de Marzo por el cual el gobierno encabezado por el Cnel. Rafael Franco estipulaba que:

Quedan cancelados para siempre de los Archivos Nacionales reputándoselos como no existentes todos los decretos-líbelos dictados contra el Mariscal Presidente de la República del Paraguay don Francisco Solano López, por los primeros Gobiernos establecidos en la República a raíz de la conclusión de la guerra de 1865 (Decreto $N^{\circ}$ 66. Artículo $1^{\circ}$. Asunción, marzo $1^{\circ}$ de 1936).

De esta forma, de un solo plumazo, el gobierno eliminaba los decretos antilopiztas, tratando, con esta obra, eliminar toda mancha que pese sobre la figura del Mcal. Francisco Solano López. Debemos tener en cuenta, que la construcción de un héroe, así como de varios mitos, va asociado al proceso de fortalecimiento de una Nación, que necesita sustentar la identidad nacional, a través de un símbolo poderoso que encarne los ideales y las aspiraciones de un determinado pueblo y responda a un proceso complejo, cuyo objetivo final sea la de unir y acentuar el sentido de comunidad. Al decir de Dukheim, "es al repetir el mismo grito, pronunciar la misma palabra, o ejecutar el mismo gesto en relación a algún objeto (los individuos) se sienten y se convierten en una unidad" (Guibernau, s.a.: 98).

La obra del gobierno de Franco no sólo se remitió a la eliminación definitiva de los documentos que atacaban la figura del Mcal. López. En el artículo $2^{\circ}$ del 
mismo decreto se estipuló: "Declarase Héroe Nacional sin ejemplar al Mariscal Presidente de la República del Paraguay don Francisco Solano López, inmolado en representación del idealismo paraguayo, con sus soldados, en la Batalla de Cerro Corá el $1^{\circ}$ de Marzo de 1870" (Decreto $\mathrm{N}^{\circ} 66$. Artículo $2^{\circ}$. Asunción, marzo $1^{\circ}$ de 1936). Con este artículo se daba un giro al papel que ocupaba el Mcal. López en la historia nacional.

De esta forma pasaba de ser asesino de su patria, culpable del genocidio de su pueblo y la destrucción del país a ser "Héroe Máximo" de la Nación. La razón de este decreto obedece a

\begin{abstract}
Que es tiempo de elevar los corazones hasta la ofrenda final de una consagración pública que interprete la reivindicación de todo el pasado del Paraguay y de la memoria incomparable de su Mariscal Presidente, único jefe de Estado que murió con las armas en la mano en nombre de un ideal de civilización humana (Decreto $N^{\circ}$ 66. Asunción, marzo $1^{\circ}$ de 1936).
\end{abstract}

En el mismo decreto se fijaba la erección de "un gran monumento conmemorativo sobre la más alta colina sita a orillas del río Paraguay a la entrada de la Ciudad de la Asunción" (Decreto $N^{\circ} 66$. Artículo $3^{\circ}$. Asunción, marzo $1^{\circ}$ de 1936) y se autorizaba al Ministerio del Interior a ponerse de acuerdo con la Comisión Pro-homenaje, cuya tarea era la de organizar todo lo concerniente con el homenaje. Luego de sesenta y seis años la figura del Mcal. López era reivindicada por el Estado paraguayo.

A partir de este decreto el Mcal. López se convierte en la figura histórica alta de la Nación Paraguaya y "es nuestro deber honrar su memoria esclarecida tanto como seguir su ejemplo". ${ }^{12}$ Para honrar la memoria del héroe nacional fue establecido un monumento que reúna a los beneméritos de la Patria. "Designase con el nombre de Panteón Nacional el monumento expresado y destínasele en tal carácter a conservar los restos de los Próceres beneméritos de la Nación que se hicieron merecedores de la gratitud de la posteridad de sus virtudes excepcionales al servicio del patria" (Decreto $\mathrm{N}^{\circ} 4834$. Artículo $1^{\circ}$. Asunción, septiembre 14 de 1936).

12 Discurso pronunciado por el Presidente Provisional de la República Cnel. Rafael Franco. Asunción, Marzo, $1^{\circ}$ de 1936. 
Para ello, fue necesario la expropiación de la manzana comprendida por las calles Chile, 25 de noviembre (actual Nuestra Señora de la Asunción), Palma y Estrella. "Procédase, en consecuencia, a la expropiación de las tierras que le faltan al Panteón para completar la manzana, las que serán indemnizadas por el Estado" (Decreto del 21 de diciembre de 1936. Artículo $2^{\circ}$ ).

Para depositar los restos del Mcal. López en el Panteón Nacional de los Héroes fue necesario la localización y exhumación de los restos del Mcal. López. Una vez hallados los restos fueron trasladados en el cañonero "Humaitá" a Asunción, llegando al puerto de la Capital el domingo once a las diez horas.

Los restos del Mcal. López fue depositado en el Panteón Nacional de los Héroes el día doce de octubre de 1936. "Queda cumplida asimismo la superior disposición gubernativa que ordena sean depositados en el recinto central del mismo los restos del Mariscal Presidente de la República, Don Francisco Solano López (...) El fuego de nuestro patriotismo seguirá velando junto a ellos, día y noche, hoy y siempre". ${ }^{13}$

De esta forma, la figura del Mcal. Francisco Solano López ascendió a ser considerado como el Héroe Máximo de la República del Paraguay, adquiriendo una imagen positiva y triunfal, convirtiéndose en conductor nacional y hacedor de la historia patria. "El revisionismo conllevaba la apología del gobernante fuerte, del "mesías" militar, depositario y salvador de la nacionalidad" (Cardozo, 1956: 24). Al punto de ser considerado el prohombre de la Nación y modelo a ser imitado por que reúne las características de la raza paraguaya, según la óptica de sus reivindicadores.

\section{La nacionalización del centro de Asunción}

Un fenómeno asociado al culto del Mcal. López fue la nacionalización del centro asunceno. Este fenómeno se observa a través de varios aspectos. Una de ellas es el nombre de las calles, la mayoría de ellos llevan nombres de héroes que hacen recordar acontecimientos importantes de nuestra historia. Así nombres como López, Caballero, Díaz, Iturbe, Yegros, De la Mora, Humaitá, Cerro Corá, entre otros, configuran el tejido simbólico de una Nación que "se superó en la derrota" (Capdevila, s.a.: 1). Los símbolos y

13 Discurso del Dr. Juan Stefanich, Ministro de Relaciones Exteriores e interino de Guerra y Marina. Asunción, 11 de octubre de 1936. 
los rituales son agentes determinantes en la instauración de la identidad nacional. "La conciencia de formar una comunidad se crea mediante el uso de símbolos y la repetición de rituales que inyectan energía a los miembros de la nación" (Guibernau, s.a.: 94). Esto se da a través de acontecimientos que ayuden a afianzar la unidad, como festividades, símbolos, ya sean palabras, objetos o signos, como la bandera por ejemplo.

Los edificios del centro también hacen mención al pasado nacional. Construcciones como el Palacio de López, la Catedral, el Teatro Nacional, el Panteón Nacional de los Héroes, alimentan el imaginario colectivo de un relato estructurado en torno a la figura de los López, las armas y los trofeos de guerra. De esta manera se buscó fundar la acción del presente en las raíces del pasado, en ese proceso de transformación de la sociedad.

Lo que se observa es que existe una patrimonialización de los lugares históricos mencionados, y este fenómeno se acentuó aún más bajo la dictadura Stronista (1954 - 1989), con un discurso totalitario sobre el pasado nacional, instalando "en la duración un metadiscurso sobre el pasado" (Guibernau, s.a.: 94). No debemos olvidar que la conciencia colectiva de un determinada sociedad se plasma tanto en la práctica de los sujetos como en los lugares, de ahí la importancia del diseño de los espacios públicos, de los monumentos, las corrientes estéticas, etc., que determinan e imponen, en un determinado momento de poder, determinados imaginarios sociales.

Existe una representación del pasado a través de los espacios físicos, con un claro objetivo de buscar la cohesión social, tratando de hacer recordar el heroísmo del pueblo paraguayo. Este fue el elemento del cual se valieron los distintos gobiernos autoritarios que se sucedieron en el Paraguay entre 1936 - 1989, para legitimar su poder. "Ser una historia que cada uno conoce, una historia que empapa el espacio público, que alimenta el imaginario colectivo y estructura las identidades" (Guibernau, s.a.: 94) de forma a acrecentar y reforzar el nacionalismo por medio de símbolos y creencias.

A partir de 1936, el núcleo vital del centro sube dos cuadras. Anteriormente, todas las actividades se realizaban frente al edificio del Congreso (hoy día Museo del Cabildo), pero a partir del gobierno del Cnel. Rafael Franco las actividades de diver- 
sa índole tienen como epicentro el Panteón Nacional de los Héroes, ${ }^{14}$ que se convirtió en el insignia del Nacionalismo.

El casco histórico asunceno se convirtió así en un espacio que busca constituir un relato de la historia, pero un relato que interprete el pasado nacional signado por el sacrificio y el heroísmo, buscando sistematizar las referencias a la guerra grande, tratando de lograr arraigar el metadiscurso del pasado en la memoria colectiva. Se trata también de un dispositivo simbólico de transmisión de la memoria colectiva de forma intergeneracional y de afirmación de las ideas y sentimientos colectivos que afirman la unidad y la personalidad de la sociedad.

\section{Conclusiones}

El gobierno instalado a partir de febrero de 1936 instauró un nuevo modelo político, acorde a las transformaciones ideológicas operadas a nivel mundial y creó las condiciones objetivas para la instauración del Nacionalismo como Política de Estado. De tinte totalitario, la presidencia del Cnel. Rafael Franco, imprimió cambios que abarcaron diversos aspectos de la vida nacional. Uno de los aspectos revisados por este gobierno fue el revisionismo histórico, campaña ya iniciada desde fines del siglo XIX.

El nuevo régimen instaurado tras la revolución de 1936 adoptó el Nacionalismo como Política de Estado, volviéndose a partir de allí un elemento gravitante en el sistema político. La adopción del Nacionalismo implicó una revisión del pasado nacional, con el objetivo de reivindicar figuras de la historia patria que habían sido vejados y olvidados por el modelo político implantado en el país tras la culminación de la Guerra contra la Triple Alianza, siendo considerados a partir de allí, los gobiernos de Francia y Carlos A. López, como modelos a seguir, al considerar, sus respectivos gobiernos, como paradigmas a imitar y posibilitó el triunfo del imaginario político militar nacionalista, que años más tarde, se trasformará en católico y colorado.

Una de las primeras medidas que adoptó el gobierno de Franco fue la de erigir la figu-

14 Tanta es la significación que adquiere este edificio que si uno observa y compara el billete de 1000 guaraníes con la moneda del mismo monto, uno puede notar la diferencia. En el billete está impreso la nomenclatura de Oratorio de Nuestra Señora de la Asunción y Panteón Nacional de los Héroes; pero en la nueva moneda sólo se observa la inscripción Panteón Nacional de los Héroes. 
ra del Mariscal Francisco Solano López en calidad de "Héroe Máximo", eliminando con un solo documento todos los decretos que fueron elaborados contra la figura del Mcal. López. Con esta obra demostró claramente la tendencia de su gobierno con respecto a la campaña revisionista, emprendida por varios intelectuales desde varios años atrás.

El discurso de Estado mostró claramente su directriz nacionalista, reformulando las funciones del Estado y de la sociedad simbólica. Frases como revolución nacionalista, identidad nacional, intereses vitales de la nación, entre otros, demarcaban el camino a seguir por el nuevo estado. Consideramos también, que el resurgimiento del nacionalismo tuvo mucho que ver con el papel cumplido por la milicia, estamento social que a partir de 1936 tuvo una injerencia directa en el quehacer político.

Por medio de varios decretos, el gobierno de 1936, mostró su política nacionalista, dando, inclusive, una nueva relectura y reescritura de la historia nacional, llegando a concretarse, lo que Eric Hobsbawm considera el tercer estadio del Nacionalismo. De alguna forma, el Nacionalismo, entraña también la pretensión de instaurar una especie de filosofía de la Historia, una visual con la que captar el sentido y la razón de lo sucedido a lo largo del tiempo.

Con respecto a este último punto, la lucha por la memoria, debemos recordar, que no sólo se limita al pasado, ya sea este remoto o mediato, sino también a lo cotidiano y como señala Ricoeur, la memoria colectiva es frágil por que los sustentos de la misma están constantemente debatidas, y nuevos hechos sociales y políticos van hilando y edificando memorias emergentes.

Es interesante observar cómo se fue perfilando y consolidando las características básicas de la historia paraguaya. La simbiosis de revisionismo histórico y la adopción del Nacionalismo como Política de Estado a partir de 1936, provocó la instauración y consolidación de las tres categorías epistemológicas de nuestra historia: el mito del eterno retorno, el maniqueísmo y el mito del héroe máximo.

A pesar de la prematura caída del gobierno de Rafael Franco, su obra perduró por muchos años, inclusive hoy la seguimos observando, sin que la mayoría pueda percatarse de ello, debido a que nuestras estructuras mentales se han acostumbrado a las mismas o a repetir lo que se ha dicho por muchos años, sin detenernos a reflexionar. No debemos olvidar que al estudiar el Nacionalismo, no sólo debemos remitirnos al aspecto político, sino también analizar todo lo referente a los sentimientos y las emociones. 
No pretendemos desmoronar mitos o creencias algunas. Sólo poner al tapete un tema que consideramos es de suma importancia para nuestra historia, ahora que nos encontramos tan cerca de un acontecimiento crucial para nuestra existencia como Nación, como lo es el Bicentenario de nuestra independencia. Nuestra intención es llamar la atención sobre el imprescindible conocimiento y estudio de la historia como una forma de superarnos como pueblo.

\section{Referencias bibliográficas}

BAREIRO SAGUIER, Rubén. 1990. (1978). "La generación nacionalista indigenista del Paraguay y la cultura guarani". En: De nuestras lenguas y otros discursos. Asunción: UCA, Biblioteca de Estudios Paraguayos, p. 115-122.

BOBBIO, Norberto, Incola MATTEUCCI y Gianfranco PASQUINO (2000). Diccionario de Política. $12^{\circ}$ edición. T. II. Madrid: Ed. Siglo Veinte.

BOSIO, Beatriz G. y Eduardo Devés - Valdés (2006). Pensamiento Paraguayo del Siglo XX. Asunción: Ed. Intercontinental.

BRAY, Arturo (1981). Armas y Letras. Memorias. Tomo II. Asunción: Ed. Napa.

BREZZO, Liliana M. (2005). Aislamiento, Nación e Historia en el Río de la Plata: Argentina y Paraguay. Siglos XVII - XX. Instituto de Historia. Fac. de Derecho y Ciencias Sociales del Rosario, pp. 272-301.

CARDOZO, Efraím (1996). Paraguay Independiente. Asunción: Ed. El Lector.

CARDOZO, Efraím (1996). Historia Cultural del Paraguay. Asunción: Ed. El Lector.

CARRÓN, Juan M. y otros (2004). El Régimen Liberal. 1870 - 1930. Sociedad, Economía y Cultura. Asunción: Ed. Arandura.

CÉSPEDES, Roberto (1983). El Febrerismo: Del Movimiento al Partido. 1936/1951. Asunción: Ed. Luxe.

CÉSPEDES, Roberto (2008). El otro-enemigo de la Nación. En: “El Paraguay Eterno" de J. Natalicio González, pp. 1-28.

CREYDT, Oscar (2007). Formación histórica de la Nación Paraguaya. Asunción: Ed. Servilibro.

CHIAVENATO, Julio José (1979). A guerra do Chaco (leia-se petróleo). San Pablo: Ed. Brasiliense. 
DELICH, Francisco (2007). Sociedades Invisibles. La cultura de la ingobernabilidad en América Latina. Ed. Gedisa, Buenos Aires, 206 p.

DORATIOTO, Francisco Fernando. (en línea). El Nacionalismo lopizta paraguayo. http://www.cerventesvirtual.comHemeroteca>América sin nombre (publicaciones periódicas). ( $\mathrm{N}^{\mathrm{o}} 4$, Diciembre de 2002).

FUSI, Juan Pablo. (ABC, 28-10-2002). El Nacionalismo en el siglo XX.

GAONA, Francisco (1990). Introducción a la Historia Gremial y Social del Paraguay. Tomo III. Asunción: Ed. R.P.

GELLNER, Ernest (1997). Naciones y Nacionalismos. Ed. Alianza: Buenos Aires.

GIL DELANOI, Pierre-André Tagieff (1993). Teorías del Nacionalismo. Barcelona: Ed. Paidós.

HALPERIN DONGUI, Tulio (1989). Historia Contemporánea de América Latina. México: Ed. Alianza.

HERNÁNDEZ SAMPIERI, Roberto y otros (2004). Metodología de la Investigación. Tercera Edición. México: Mc Graw Hill.

HIRSCH, Joachim. (ABC, 28-10-2002). Transnacionalización y renacionalización. Estado Nacional, nacionalismo y conflicto de clases.

HOBSBAWM, Eric (1998). Naciones y Nacionalismos desde 1870. 2da. Edición. Barcelona: Ed. Crítica.

IRALA BURGOS, Adriano (2003). La Epistemología de la historia en el Paraguay, en: Revista Paraguaya de Sociología. Año 40. № 116, Enero-Abril, de 2003. Asunción, CEPS.

JOVER PERALTA, Anselmo (1982). El Paraguay Revolucionario. Asunción: Ed. La República.

MALAMUD, Carlos (2007). Historia de América. Madrid: Ed. Alianza.

MONIZ BANDEIRA, L.A. (1998). A Guerra do Chaco. En: Revista brasileña de Politica. Int. 41, p. 161-200.

MONTENEGRO GONZÁLEZ, Augusto (s.a). Historia de América., Bogotá: Ed. Norma O’LEARY, Juan (1982). Prosa Polémica. Asunción: Ed. Napa. 
PANGRAZIO, Miguel Ángel (2008). Guerras civiles, revoluciones y asonadas en el Paraguay. Asunción: Ed. Intercontinental.

PASTORE, Carlos (1948). La lucha por la Tierra en el Paraguay. Proceso histórico y legislativo. Montevideo: Ed. Antequera.

RAHI, Arturo (1988). La entrega del Chaco y otros capitulos de la Historia paraguaya. Asunción: Carlos Schauman editor.

RAHI, Arturo (2001). Franco y la revolución de febrero. 2da. edición. Asunción: Augusto Gallegos editor.

RIVAROLA, Milda (2001). Filosofías, Pedagogías y percepción colectiva de la historia en el Paraguay, en: Revista de Sociología. Año 38, N 111/112. Asunción: CPES.

RODRÍGUEZ ALCALÁ, Guido (1987). Ideología Autoritaria. Asunción: R.P. Ediciones.

SMITH, Anthony (2001). Nacionalismo. Madrid: Ed. Alianza.

SPERATTI, Juan (1984). La Revolución del 17 de febrero de 1936. Gestación-Desarrollo-Ideología-Obras. Asunción.

STEFANICH, Juan (1946). Renovación y Liberación. La obra del Gobierno de Febrero., Buenos Aires: Ed. Nuevo Mundo.

STEFANICH, Juan (1959). El 23 de octubre de 1931. Buenos Aires: Ed. Febrero.

VIOLA, Alfredo. (s.a.). Eligio Ayala. Presidente Constitucional 1924-1928. Asunción.

WHIGHAM, Thomas Lyle (2006). La Guerra destruye, la Guerra construye. Ensayo sobre el desarrollo del nacionalismo en Sudamérica. Nuevo Mundo Mundos Nuevos, Número 6-2006, mis en ligne le 20 mars 2006, réference du 16 juillet 2007, disponible sur: http// nuevomundo.revues.org/document2074.htm/.

\section{Decretos}

Decreto $\mathrm{N}^{\circ} 23$. Asunción, febrero 26 de 1936.

Decreto $\mathrm{N}^{\circ} 66$. Asunción, marzo $1^{\circ}$ de 1936.

Decreto No 514. Asunción, marzo 31 de 1936.

Decreto No 4834. Asunción, septiembre 14 de 1936. 
Decreto-Ley No 6227. Asunción, noviembre 2 de 1936.

Decreto-Ley No 10.680. Asunción, abril 17 de 1936.

Decreto No 2118. Asunción, junio 18 de 1936. 